\title{
New records of genera and species of myxomycetes (Amoebozoa) from the Neotropics
}

\author{
Carlos Lado ${ }^{1}$, Arturo Estrada-Torres ${ }^{2}$, Carlos Rojas ${ }^{3,4}$ \\ 1 Real Jardín Botánico (RJB, CSIC), Plaza de Murillo 2, 28014 Madrid, Spain. 2 Centro Tlaxcala de Biología de la Conducta, Universidad \\ Autónoma de Tlaxcala, Km 1.5 carretera Tlaxcala-Puebla s/n, 90070, Mexico. 3 Engineering Research Institute, Universidad de Costa Rica, San \\ Pedro de Montes de Oca, 11501-Costa Rica. 4 Experimental Interdisciplinary Station of Agroecological Models (FEIMA), University of Costa \\ Rica, Turrialba, 30502-Costa Rica. \\ Corresponding author: Carlos Rojas, carlos.rojasalvarado@ucr.ac.cr
}

\begin{abstract}
During field surveys of myxomycetes in Central America, 2 previously unrecorded genera and 4 species, viz. Craterium muscorum Ing, Dictydiaethalium dictyosporum Nann.-Bremek., Physarina echinocephala Höhn, and Stemonaria rufipes, were identified. Some of these are new for the Neotropics. These noteworthy range extensions of these species to the Mesoamerican biodiversity hotspot adds to our knowledge of rarely recorded myxomycetes worldwide. Images of the more relevant taxonomic characters are provided, and for some species, this is the first illustrations with macro and microphotographs and scanning electron microscopy images.
\end{abstract}

\section{Keywords}

Biodiversity; geographical distribution; Mesoamerica; SEM.

\section{Introduction}

The myxomycetes have been documented in Central America for over 100 years (Lado and Wrigley de Basanta 2008). In this geographical area, the implementation of regional research agendas relating to myxomycetes has been limited by the centralization of biological research in Costa Rica and Panama. Despite this, a recent effort to normalize the investigation on myxomycetes in the northern part of Central America has generated recent advances (Morales 2017).

Based on the scant historical efforts to investigate myxomycetes in Central America (see Rojas and Doss 2013), it is not surprising to discover new records for these microorganisms in such region. However, given the limited availability of basic taxonomic information on some rarely documented species on the global level (Lado and Eliasson 2017), such task is highly significant to strengthen the current catalog of data on myxomycetes.

The latter is particularly relevant for a group of microorganisms which has not received much attention from scientists carrying out broader types of analyses. Despite this fact, some efforts to address large-scale population assessments (e.g. Rojas et al. 2011, Lado et al. 2013, 2014), including assessing worldwide patterns of distribution (Aguilar et al. 2014) and biogeography (e.g. Estrada-Torres et al. 2013, Dagamac et al. 2017), have been carried out. These works have allowed a better understanding of myxomycete distribution across 
different ecosystems and geographical localities. However, large informational gaps still exist for most rarely recorded species.

In the present work, 4 undocumented species for Central America are described, illustrated and commented upon. The objective of this effort is to provide the community of researchers in the field of microbial biology with integrated taxonomic and ecological data on the myxomycete species being considered. This is important since it provides new information for more accurate taxonomic identifications and higher resolution ecological analyses.

\section{Methods}

For the present study, 3 of the specimens were collected as part of research expeditions made by all the authors and 1 was isolated in a moist chamber culture. All collections were made in Costa Rica between 2015 and 2017, under the framework of Costa Rican Law 7788 (article 4 and transitory) and Resolution 5861-2005 from University of Costa Rica.

Field collections were made using the opportunistic method described by Cannon and Sutton (2004). Following this method, substrates where fruiting bodies of myxomycetes tend to develop were surveyed. When myxomycetes were discovered, they were extracted and placed in small cardboard boxes for identification and storage. The specimen collected from a moist chamber appeared on ground litter as a substrate. For this method, explained by Stephenson and Stempen (1994), the decomposing plant material was placed in a Petri dish previously lined with filter paper and water was added. After 24 hours, excess water was discarded, and the moist chamber was kept under observation for 10 weeks. In a similar manner, for the field collections, once the fruiting bodies were identified, they were extracted and placed in small cardboard boxes for additional study.

For identification, all microscopic measurements, observations and illustrations were made using a Nikon Eclipse 80i microscope with Nomarski interference contrast and a Leica M205 stereomicroscope provided with a digital camera. The material was mounted directly in Hoyer's medium or polyvinyl alcohol (PVA). Three of the species considered in this study were also observed under a scanning electron microscope to analyze ultrastructural details, whereas the fourth one was not examined this way due to limited material. All the selected specimens were treated with the critical point dried material technique, and all the observations were made in the Real Jardín Botánico, CSIC, using a Hitachi S-3000N scanning electron microscope at $10-15 \mathrm{kV}$. Color notations are from the ISCC-NBS Color Name Charts Illustrated with Centroid Colors (Kelly 1965). Nomenclature of the species follows Lado (2005-2018). For the description of the spores using SEM, the terminology proposed by Rammeloo (1974, 1975) has been utilized. A description of specimens of each species is provided, along with taxonomic comments relating to either the original descriptions or other relevant observations on distribution made by other authors. Forest classification follows Holdridge (1967).

\section{Results}

The 4 species considered in the present work represent new records for the Central American region and for Costa Rica. Three of these species also represent new records for the Neotropics. The collecting location of each specimen is presented in Figure 1.

\section{Craterium muscorum Ing}

Trans. Brit. Mycol. Soc. 78(3): 443 (1982)

Figures 2-8

New record. Costa Rica, San José Province, Dota County, in a patch of forest on $\mathrm{km} 77$ of the Southern Interamerican Route $\left(09.6154^{\circ} \mathrm{N}, 083.8192^{\circ} \mathrm{W}\right.$, ca 3000 m), Arturo Estrada-Torres, 2 March 2016, on bryophytes, in evergreen lower montane wet forest, MA-Fungi 91170.

Description. Sporocarps grouped or scattered, stalked, 1.6-2 $\mathrm{mm}$ in total height. Sporotheca subglobose, 0.6$0.8 \mathrm{~mm}$ diameter, blackish (65. br. Black-62. d. gy. Br). Hypothallus membranous, blackish. Stalk stout, erect, cylindrical, attenuate toward the apex, 1-1.3 mm long, dark brown to blackish (65. br. Black-62. d. gy. Br), filled with whitish, rhombic crystals of lime. Peridium single, membranous, slightly iridescent, dark grayish brown (62. d. gy. Br), blackish toward the base, slightly paler toward the apex, orange brown (54. br O-55. s. Br) by transmitted light; dehiscence irregular, by the upper part of the sporotheca, the basal part remaining like an irregular calyculus. Columella concolour with the stalk, whitish in the upper section, capitate form, reaching the middle of the sporotheca, filled with lime. Capillitium rigid, almost entirely limy, fragile, merging with the columella, branched and anastomosed, as a whitish tridimensional net, filled with lime. Spores free, black in mass, dark brown (59. d. Br-61. gy. Br) by transmitted light, subglobose, 12.5-15 $\mu \mathrm{m}$ diameter, reticulated, sometimes with the reticulum broken by Light Microscopy, simple reticulate type under SEM, sculptured with muri of $1-1.3 \mu \mathrm{m}$ height, making a small number of meshes to a hemisphere. Plasmodium not observed.

Notes. Lister and G. Lister (1904), who originally described this species as Badhamia rubiginosa var. globosa Lister \& G. Lister, found it in the north of Wales at the end of the 19th and beginning of the 20th century and mentioned that this species was "always occurring on moss and ferns growing on wet rocks" in ravines. Martin and Alexopoulos (1969) included it as a synonym of Badhamia obovata (Peck) S.J. Smith (as var. globosa), but Ing (1982) clarified the nomenclatural status of this species.

The known distribution of the species according to Lister (1925) was limited to Great Britain, Ireland, Ger- 


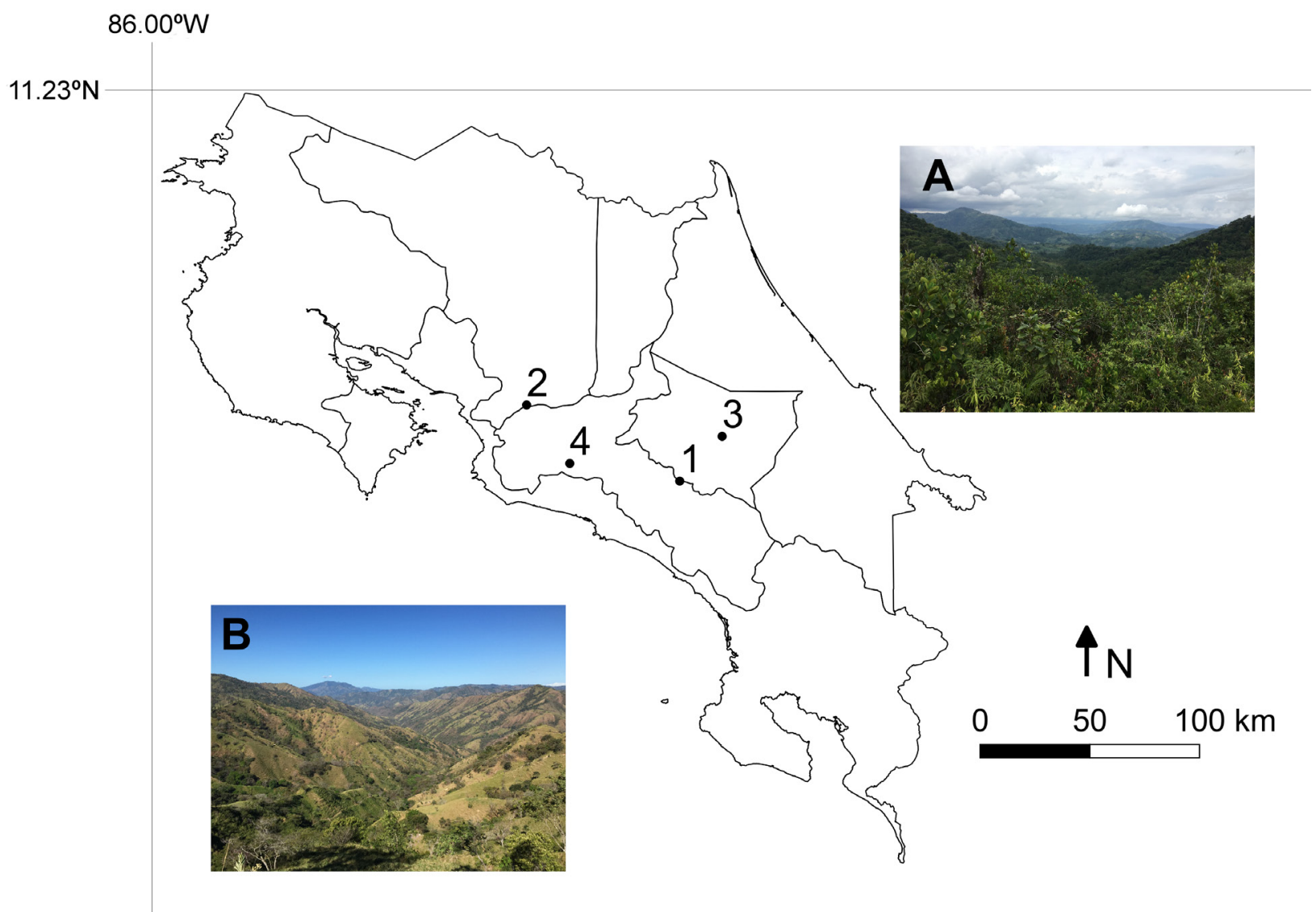

Figure 1. Map of Costa Rica showing the collecting locations for 1) Craterium muscorum, 2) Dictydiaethalium dictyosporum, 3) Physarina echinocephala and 4) Stemonaria rufipes. Forests are seasonal on the Pacific slope (A: 2 and 4) and non-seasonal on the Caribbean slope (B: 1 and 3$)$.

many (Hosltein) and the Sandwich Islands in the South Pacific Ocean. According to the Global Biodiversity Information Facility (GBIF) data portal, some specimens also have been found in France, other parts of Germany and Nepal. Stojanowska and Panek (2003) also reported it from Poland. The present record represents the first one for the American continent and the entire Neotropical region and widely broadens the known distribution of the species. Interestingly, this specimen was found in the Cerro de la Muerte area, previously reported as a region where myxomycete assemblages include species traditionally associated with temperate areas (Leontyev et al. 2014, Rojas et al. 2015). The affinity of this species for bryophytes and colder wet environments is supported by the present study.

This species is very similar to Craterium dictyosporum (Rostaf.) H. Neubert, Nowotny \& K. Baumann, but the reticulation of the spores, which is strongly marked, almost complete (Figs 7, 8), and with a prominent edge in C. muscorum, sets them apart. In addition, the lack of lime in the peridium (Fig. 2), very evident in C. dictyosporum, is also an important difference.

\section{Dictydiaethalium dictyosporum Nann.-Bremek.}

Proc. Kon. Ned. Akad. Wetensch., C. 69(3): 345 (1966)

Figures 9-17
New records. Costa Rica, Alajuela Province, Atenas County, in a pasture about $2 \mathrm{~km} \mathrm{SW}$ of Escobal $\left(09.9297^{\circ} \mathrm{N}, 084.4520^{\circ} \mathrm{W}\right.$, ca $\left.330 \mathrm{~m}\right)$, Arturo EstradaTorres, 4 March 2016, on decayed wood, in a seasonal premontane moist forest, MA-Fungi 91171.

Description. Sporocarps densely packed as a pseudoaethalium, at maturity simulating an aethalium, effused to pulvinate, depressed, 5-10 × 1.2-2.5 mm, olive brown (95. M. Ol Br-94. L. Ol Br). Sporocarps sessile, concrescent to coalescent, closely compacted in a palisade layer, cylindrical. Hypothallus dark brown, protruding from the pseudoaethalium. Peridium single, membranous, slender and evanescent at the base, persistent at the apex as plates of 75-150 $\mu \mathrm{m}$ diameter, slightly polyhedral to rounded, dark grayish brown (62. d. gy. Br), dark yellow (88. d. Y) by transmitted light; dehiscence apical by breaking between the plates. Columella absent. Capillitium absent. Pseudocapillitium thread-like, olivaceous (94. 1. Ol Br), fading to darker (95. m. Ol Br), hanging from the borders of the peridial plates, visible only after dehiscence, the threads 1-2 mm long, flat, 7-12 $\mu \mathrm{m}$ diameter, translucent, yellowish (86. 1. Y-90. gy. Y) by transmitted light, smooth but with a fringe of around $2 \mu \mathrm{m}$ wide in one side, sometimes undulate. Spores free, dark yellow (88. d. Y) in mass, pale yellow (89. p. Y-90. gy. Y) by transmitted light, subglobose, 12.5-14 $\mu \mathrm{m}$ diameter, banded 

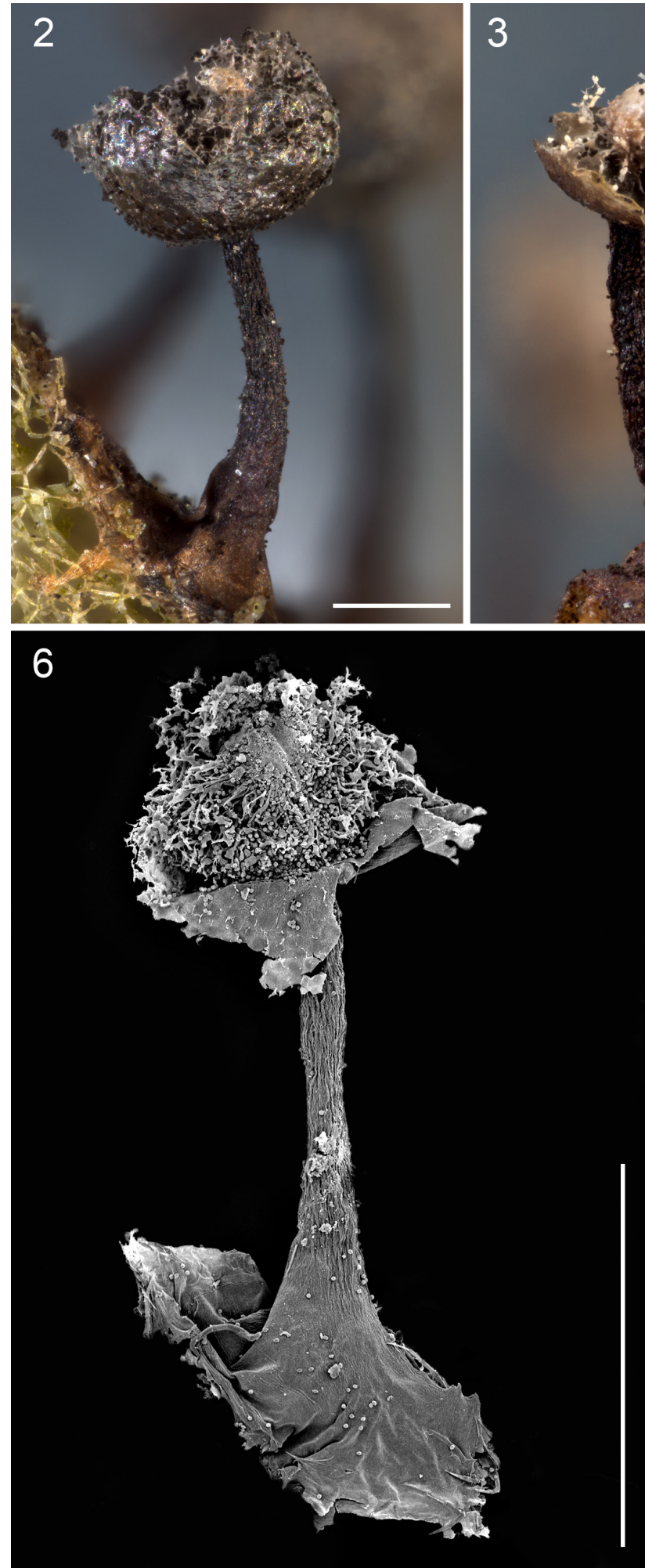

3

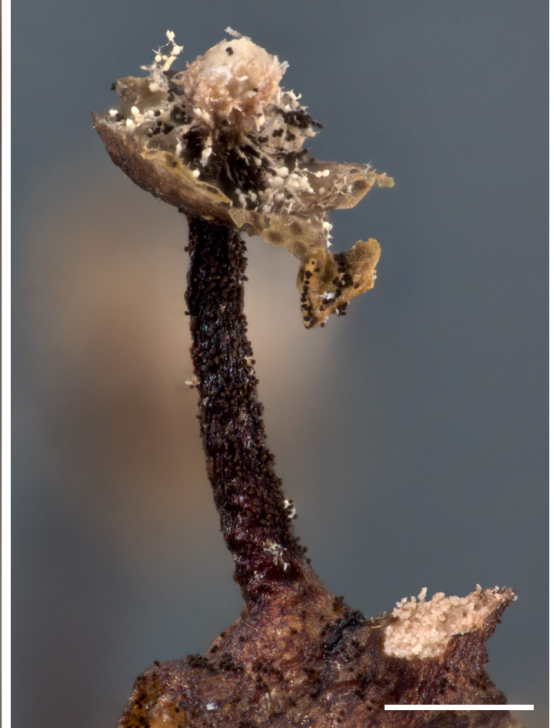

4

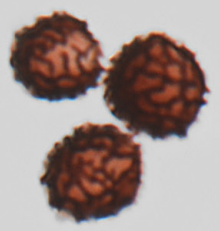

5

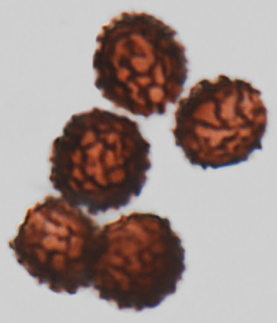

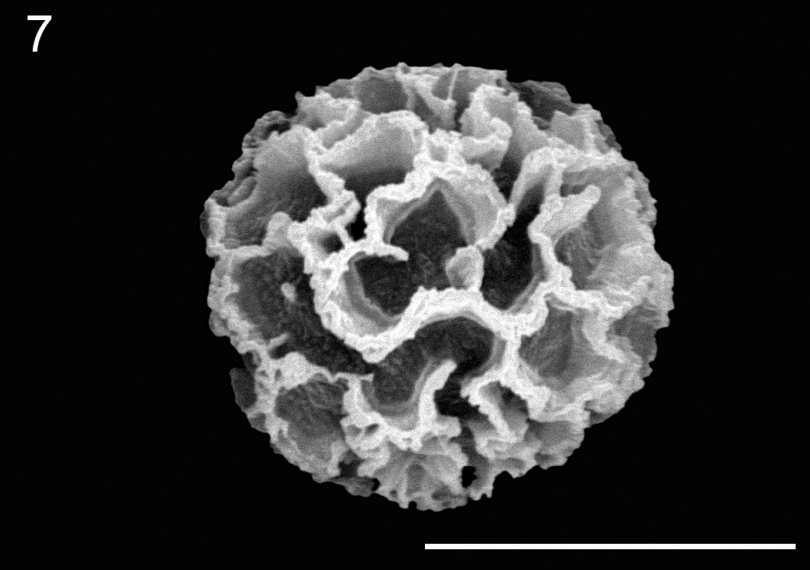

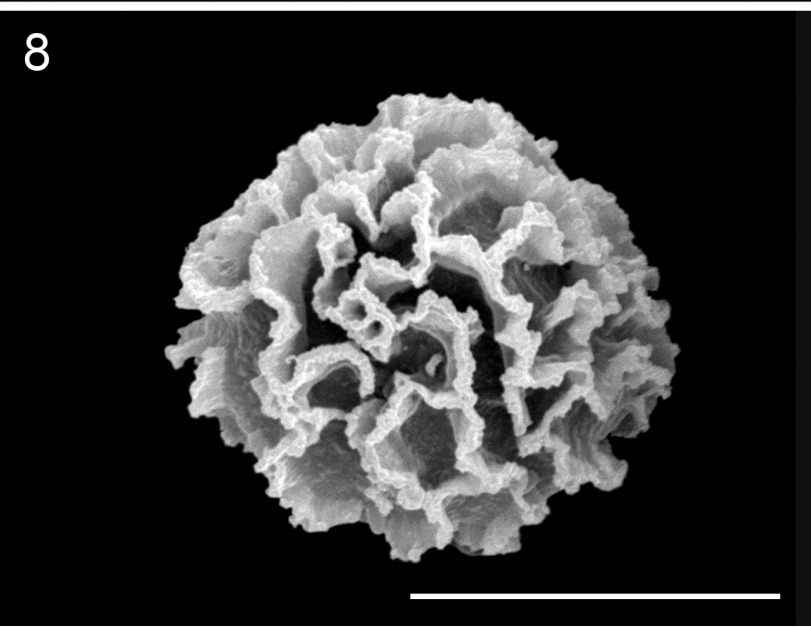

Figures 2-8. Craterium muscorum Ing (MA-Fungi 91170). 2. Stipitate sporocarp. 3. Sporocarp showing the columella. 4-5. Reticulate spores by LM. 6. Sporocarp under SEM. 7-8. Spores under SEM showing the ornamentation reticulate type, sculptured with muri. Scale bars $2-3=$ $0.5 \mathrm{~mm} ; 4-5,7-8=10 \mu \mathrm{m} ; 6=1 \mathrm{~mm}$.

reticulated, the meshes small, about $1 \mu \mathrm{m}$ across and bands about $1 \mu \mathrm{m}$ high by LM, densely pilate to simple reticulate type under SEM, sometimes the reticulum is broken. Plasmodium not observed.

Notes. This species was described by NannengaBremekamp (1966) on wood collected during 1914 in New Caledonia (in the subregion of Melanesia, in the southwest Pacific). The material is conserved in the BM herbarium and no additional specimens have been published except for a record reported by Keller (1973) for the Florida Everglades (USA), identified by NannengaBremekamp; a collection made by H. Seraoui (5 October 2007, HS 3379) on decayed wood in New Caledonia (again), deposited in Marianne Meyer's collection under 

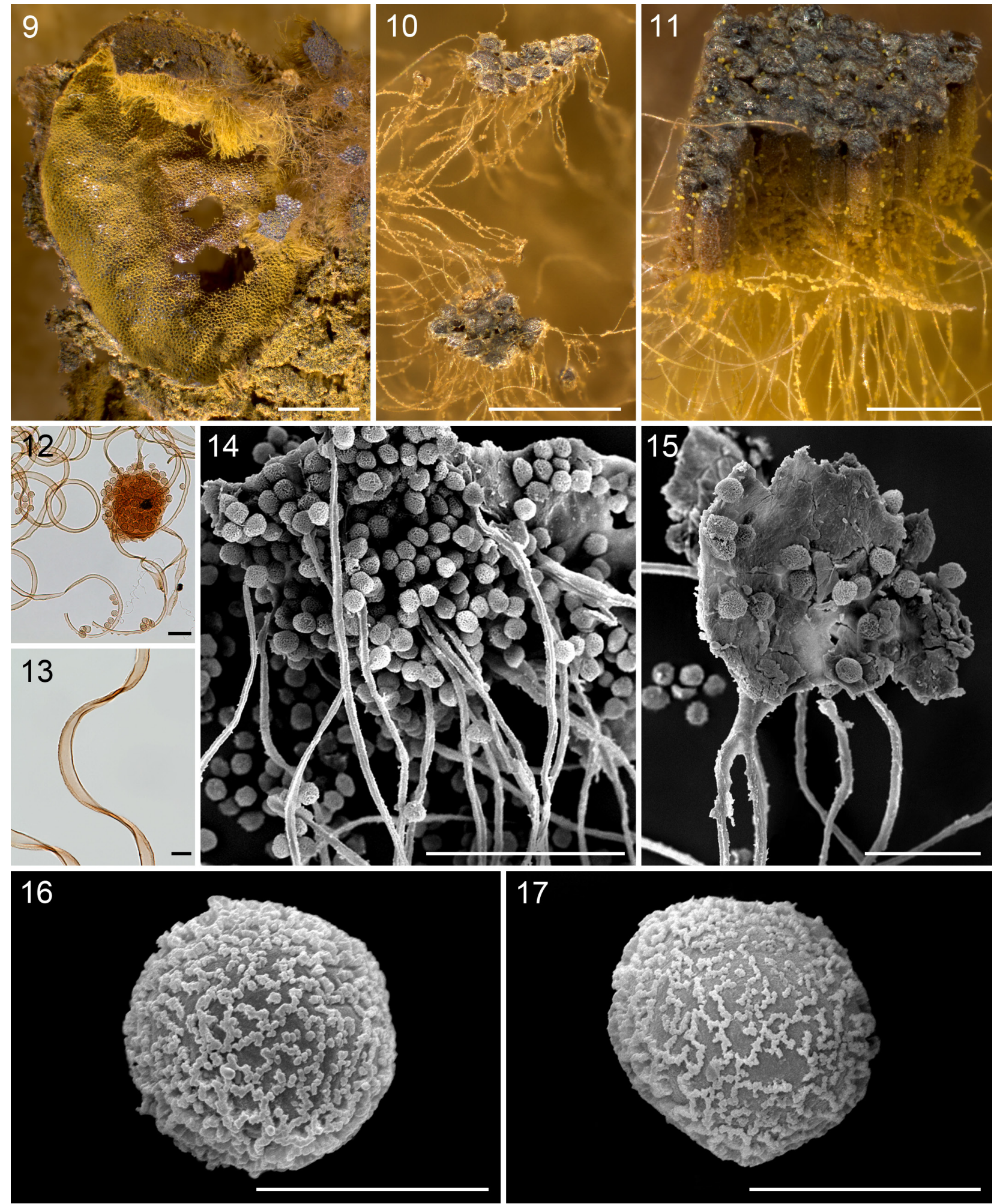

Figures 9-17. Dictydiaethalium dictyosporum Nann.-Bremek. (MA-Fungi 91171). 9. Sporocarps densely packed as a pseudoaethalium. 10-11. Sporocarps showing the remaining peridium and the pseudocapillitium thread-like. 12. Plate of the peridium with pseudocapillitium under LM. 13. Flat and undulated pseudocapillitial thread, tape-like by LM. 14-15. Plate of the peridium and pseudocapillitium under SEM. 16-17. Spores under SEM. Scale bars $9=2 \mathrm{~mm} ; 10=1 \mathrm{~mm} ; 11=0.5 \mathrm{~mm} ; 12=50 \mu \mathrm{m} ; 13=10 \mu \mathrm{m} ; 14-15=100 \mu \mathrm{m}: 16-17=10 \mu \mathrm{m}$.

number MM30415 (Poulain et al. 2011); and a report from Ranade et al. (2012) for India. In the BR herbarium, according to the GBIF data portal (https://www.gbif.org/ occurrence/665667634), there is a specimen from Florida with an identical collecting date and location as Keller's material and probably corresponds to this specimen. The record presented herein is the fifth globally, and the first one for Central America and the Neotropics. It is interesting to note that all reports have been made in tropical/ subtropical areas with strong seasonality. The record from Florida and one from New Caledonia were collected in October during the fall and the record from Costa Rica 

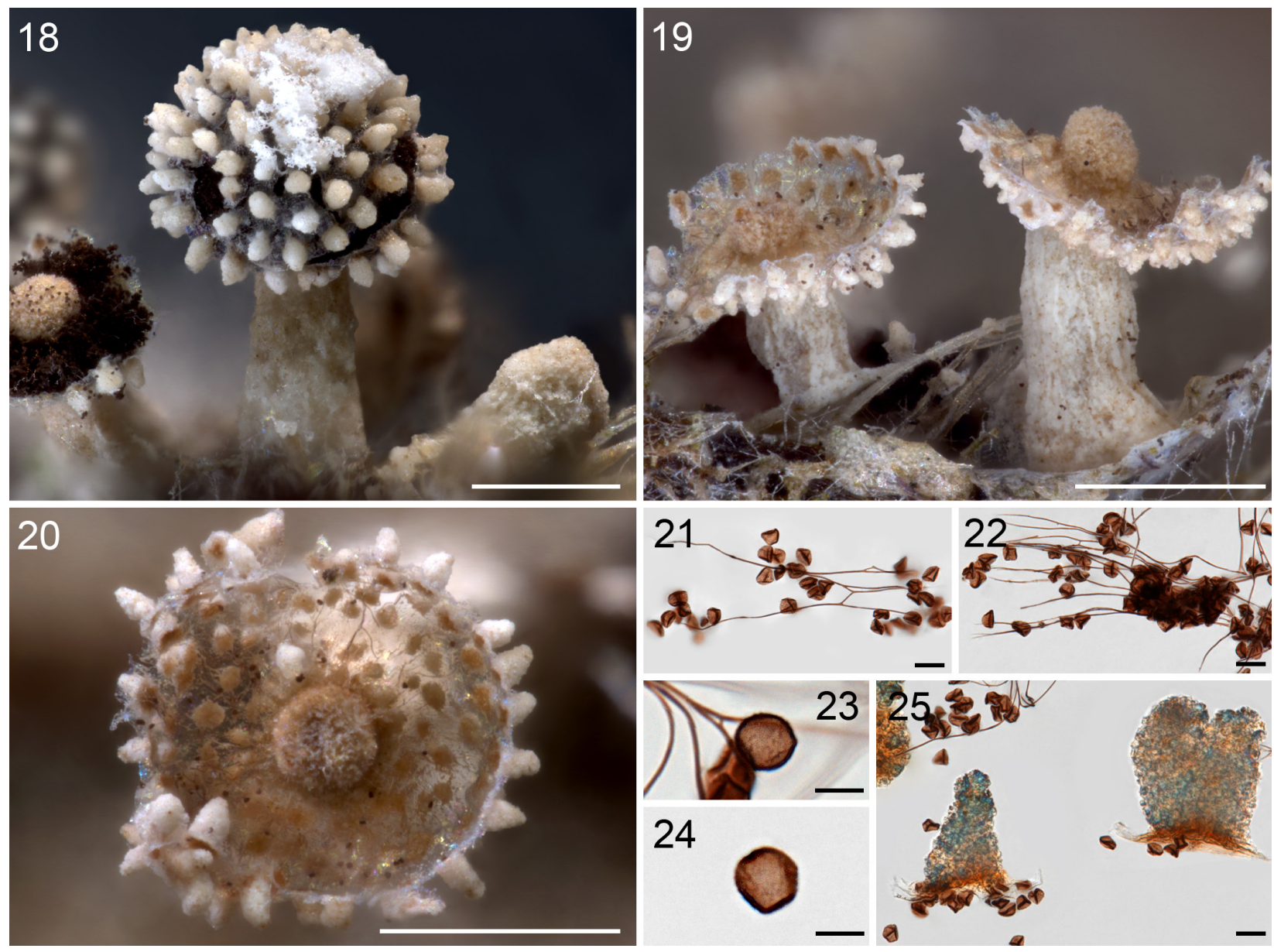

Figures 18-25. Physarina echinocephala Höhn. (MA-Fungi 91172). 18. Sporocarp showing the typical lime projections of the sporotheca, radiating from the peridial membrane. 19. Open sporocarps showing the columella. 20. Open sporotheca showing the peridium with brownish areola at the contact with the white spiculate projections. 21-22. Capillitial threads and spores by LM. 23-24. Spores under LM. 25 Limy spiculate projections of the peridium by LM. Scale bars $18-20=0.5 \mathrm{~mm} ; 21-22=5 \mu \mathrm{m} ; 23-25=10 \mu \mathrm{m}$.

in March during the spring. In all locations at that time of the year, the temperature is warm (around $26^{\circ} \mathrm{C}$ ) and the precipitation oscillates around 200 liters per square meter for the respective monthly period.

The distinctive character of this species is the spore ornamentation, composed by fused verrucae or little pilae, giving a reticulate pattern, sometimes broken, as observed by SEM (Figs 16, 17). The flat threads of the pseudocapillitium (Figs 12, 13), tape-like and undulated, also contribute to the characterization of the species. In the specimen examined in the present study, the spore size is larger than the one reported by Nannenga-Bremekamp in the original description (10-12 $\mu \mathrm{m}$ diameter). The same was observed by Keller for the Florida specimen.

\section{Physarina echinocephala Höhn.}

Sitzungsber. Kaiserl. Akad. Wiss., Math.-Naturwiss. Cl. 118:432 (1909)

Figures 18-25

New record. Costa Rica, Cartago Province, Turrialba County, in ravine next to a creek, about $0.6 \mathrm{~km} \mathrm{SE}$ of La Esperanza de Atirro $\left(09.8003^{\circ} \mathrm{N}, 083.6439^{\circ} \mathrm{W}\right.$, ca 750 $\mathrm{m})$, Carlos Lado, 18 October 2017, on dead leaves, in an evergreen premontane wet forest, MA-Fungi 91172.
Description. Sporocarps grouped, stalked, 0.6-1 mm in total height. Sporotheca whitish, limy, subglobose, 0.4-0.6 mm diameter, with spiculate lime projections. Stalk conical, $0.3-0.5 \mathrm{~mm}$ long, whitish, colorless to pale orange yellow (73. P. OY) by transmitted light, filled with lime crystals. Peridium membranous, grayish, with many whitish, lime projections radiate from the membrane, areolate by transmitted light, colorless but brownish at the contact with the white spiculate projections, the projections $25-75 \mu \mathrm{m}$ long, in form of cones or pila, filled with lime granules; dehiscence irregular. Columella representing a projection of the stalk into the sporotheca, subglobose to dome-shaped, light yellowish brown (76. 1. y. Br), occupying a third of the sporotheca, limy. Capillitium filiform, limeless, brown (58. m. Br-59. d. Br), branched, with few anastomoses. Spores free, blackish in mass, light brown (57. 1. Br) by transmitted light, subglobose to slightly polygonal, 9-10 $\mu \mathrm{m}$ diameter, minutely warted. Plasmodium not observed.

Notes. The most prominent difference that exists for the collection checked herein and descriptions of the species in the literature, is the color of the sporocarps. Höhnel (1909) described it as brown chocolate and Lister (1925) as pale pink or flesh colored. However, Alexopoulos and 
Blackwell (1968), using a collection obtained from a culture from Durango (Mexico), described it as "brown when still moist, but turning grayish-white upon drying because of the lime which encrust them". The color of the present collection, whitish, matches the description made by the latter authors for mature forms. Also, the spores observed in the present collection have the same size (8.5-10.5 $\mu \mathrm{m}$ diameter) described by them. The darker peridium (as areoles) in the point of insertion of the peglike protuberances (Figs 20, 25) is characteristic, but not previously mentioned in the descriptions of this species. Also, the light color and tenuous ornamentation of the spores observed by transmitted light are remarkable of this species (Figs 23, 24). The capillitium observed in this collection is longer and lacks the membranaceous expansions found by Alexopoulos and Blackwell (1968) in the specimen from Mexico.

According to Alexopoulos and Blackwell (1968) and Martin and Alexopoulos (1969), this species is known only from Java, Thailand, and Mexico. Ndiritu and de Hann (2014) also reported it for the African Continent (Rwanda and Burundi). Its presence in the Turrialba region of Costa Rica seems to coincide more with the first 2 locations due to climatic similarities. At least in the mid- to southern section of Thailand and in the island of Java, premontane moist forests resemble structurally those in the Neotropics. This species may have eluded collection in other surveys in Central America due to poor surveys in ravines or riparian forests or simply because fruitings were not present when surveys were carried out. For example, it is interesting to note that the present record was found already colonized by microfungi in a dry-period window after constant rainfall during the previous weeks, suggesting that humidity may be a factor accounting for its fruiting.

\section{Stemonaria rufipes Nann.-Bremek. \& Y. Yamam.}

In Nannenga-Bremekamp, Yamamoto \& Sharma, Proc. Kon. Ned. Akad. Wetensch., C. 87(4): 456 (1984).

Figures 26-36

New record. Costa Rica, San José Province, Acosta County, next to the road along route 301 , about $1.5 \mathrm{~km}$ $\mathrm{NE}$ of Caspirola $\left(09.6882^{\circ} \mathrm{N}, 084.2736^{\circ} \mathrm{W}\right.$, ca $500 \mathrm{~m}$.), Carlos Rojas, 20 January 2015, from a moist chamber culture prepared with ground litter, in a seasonal premontane moist forest, deposited in the Myxogastrid Biorepository at the Engineering Research Institute of University of Costa Rica, Ro-6476.

Description. Sporocarps aggregated to grouped, stalked, erect, $1.3-2.5 \mathrm{~mm}$ in total height. Sporotheca cylindrical, with rounded apex and base, grayish brown to blackish (62.d. gy. Br-65. br Black), 0.3-0.4 mm diameter. Hypothallus membranous, confluent, common to several sporocarps. Stalk cylindrical, slightly attenuate toward the apex, 0.3-0.5 mm long, blackish (65. br black), hollow, opaque above, slightly pale at the base. Peridium evanescent except at the base of the sporotheca where it remains as a collar or little calyculus, membranous, translucent, colorless by transmitted light, densely granulated. Columella concolorous with the stalk, reaching the apex of the sporotheca, attenuate toward the apex, spreading as a membranous layer just at the apex. Capillitium filiform, branched and with only a few anastomoses in the interior, netted, isodiametric, dark grayish brown (62.d. gy. Br) by transmitted light, sparingly joined to the columella along its whole length, the primary branches sometimes with little membranous expansions at the connection of the columella, net with some membranous expansions at the nodes, the secondary branches in the lower part mostly united at the periphery, but not forming a surface net, with the same lumen that the internal net, sometimes with spines, the apical secondary branches ending free. Spores clustered, 3-7 spores in each cluster, strongly coherent, dark brown to blackish (62. d. gy. Br-65. br black) in mass, grayish brown (60. 1. gy. Br-61. gy. Br) by transmitted light, subglobose, slightly depressed at external pole, 9-10 $\mu \mathrm{m}$ diam, warted to spinulose, with slightly more dense ornamentation on the outside of each cluster by LM, baculate to slightly pilate under SEM. Plasmodium not observed.

Notes. This is the second record of this species worldwide, as it was previously known only from Japan as reported by Nannenga-Bremekamp et al. (1984). According to the GBIF data portal (GBIF 2016), there are 3 specimens recorded, 1 in the BR herbarium (the type collection) and 2 more, in the TNS herbarium, also from Japan. This is the first specimen of the species outside Asia, and thus the first record for the Americas and the entire Neotropics.

Its distinctive characters are the clustered spores (Figs $30,31,34,36$ ), a capillitium consisting of threads of uniform diameter, even in the primary branches, mostly united at the periphery in the lower part, but not forming a surface net, and the collar remaining at the base of the sporotheca (Figs 26-29, 32, 33). The material checked in this study differs slightly from the description made by Nannenga-Bremekamp et al. (1984) in the smaller spore clusters (3-7 spores per cluster versus 10-20 spores in the original description) and the non-piriform, ovoid or conical shape of the spores, but subglobose or even somewhat flat on the outer side. The peridium of the Costa Rican specimen is ornamented with dense papillae by transmitted light, a feature not mentioned in the original description.

The specimen of the present study was found using the moist chamber technique, in a similar manner to the original description. However, ground litter was used instead of bark. The area where the plant material was collected shows seasonality and it is under the influence of occasional tropical storms (with strong precipitation), given its short linear distance to the coast. Due to the rugged topography and sparse population, the area is not heavily influenced by human activities and thus patches of forest patches are mostly intact. 


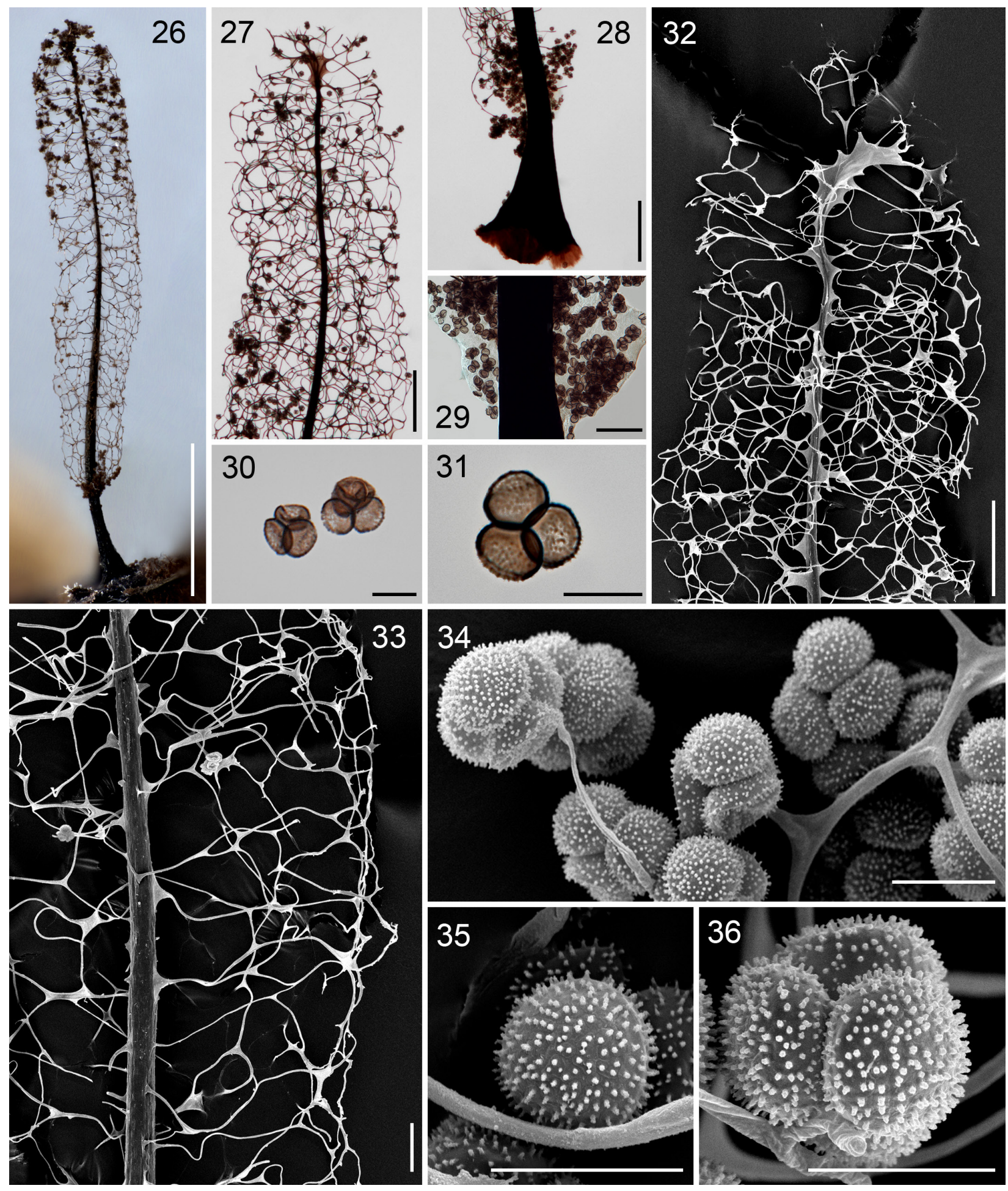

Figures 26-36. Stemonaria rufipes Nann.-Bremek. \&Y. Yamam. (Ro-6476). 26. Sporocarp. 27. Detail of the apex of the sporotheca showing the columella and capillitium. 28. Base of the stalk. 29. Remain of the peridium around the stalk. 30-31. Clusters of spores under LM. 32. Detail of the apex of the sporotheca showing the capillitial threads and the membranous expansion of the columella under SEM. 33. Capillitium sparingly joined to the columella along its whole length, the primary branches sometimes with little membranous expansions at the connection with the columella, the secondary branches united at the periphery, but not forming a surface net under SEM. 34-36. Spores clustered, three to five spores to a cluster by SEM. Scale bars $26=1 \mathrm{~mm} ; 27-28=100 \mu \mathrm{m} ; 29=50 \mu \mathrm{m} ; 30-31=10 \mu \mathrm{m} ; 32-33=100 \mu \mathrm{m} ; 34-36=10 \mu \mathrm{m}$.

\section{Discussion}

The new records presented here widely broaden the previously reported distributions of these 4 species. Their presence in the Mesoamerican Biodiversity Hotspot provides evidence to demonstrate that tropical areas, albeit hard to document, host many interesting myxomycetes for the development of taxonomic studies. Even though molecular techniques may provide important information about the identity of species making up a community, the complete characterization of species still requires morphological examination and careful descrip- 
tion of the material under examination.

The present study not only serves as a historical point acknowledging the presence of these myxomycetes in Central America, the Neotropics and the Americas, but the photographs contained in this study are among the only modern visual material of each species. As observed in the literature cited with the observations, publications including information about these 4 species appeared decades ago. This may indicate 2 different issues. First, such result could demonstrate the rarity of the species recorded herein, but second, it could be an indication of under sampling in the appropriate regions, substrates and microhabitats.

The problem is that, without more information to analyze such dichotomy, it is highly speculative to make any inference about the distribution range or the ecological status of those species. Moreover, given the small differences between the identified species and some close intra-generically related species, it is difficult to know if the same taxonomic units have been found elsewhere and misidentified. Molecular techniques could help solve this problem, but they require the primary field work, identifications and conservation of specimens. In this sense, the contribution of this study to the understanding of myxomycete biology extends to other lines of research by providing new vouchers along with ecological, geographical and temporal information.

\section{Acknowledgements}

The laboratory component associated with this study was funded by the Spanish Government through the Myxotropic Project (CGL2014-52584P) and the research activity COOPB20155 from Consejo Superior de Investigaciones Científicas (CSIC) of Spain. Additional funding, particularly for field trips, was obtained by University of Costa Rica through research project 731-B7-717 and program 731-B4-900. We also acknowledge the support of the Oficina de Asuntos Internacionales y Cooperación Externa at University of Costa Rica for funding research trips to Costa Rica of the first and second authors. Finally, appreciation is extended to a reviewer for constructive suggestions, and to Pedro Rojas, Randall Valverde, Carlos de Mier, and Yolanda Ruiz for their help during field trips, the preparation of the images for this manuscript, and the use of the SEM microscope, respectively.

\section{Authors' Contributions}

CL collected and identified part of the material, made all the descriptions and illustrations and provided funding for the laboratory component of the project. AET collected and identified part of the material and co-wrote the manuscript draft. CR collected and identified part of the material, co-wrote the manuscript draft and provided funding for the field component of the project.

\section{References}

Aguilar M, Fiore-Donno AM, Lado C, Cavalier-Smith T (2014) Using environmental niche models to test the "everything is everywhere" hypothesis for Badhamia. ISME Journal 8: 737-745. https://doi. org/10.1038/ismej.2013.183

Alexopoulos CJ, Blackwell M (1968) Taxonomic studies in the Myxomycetes. II. Physarina. Journal of the Elisha Mitchell Scientific Society 84 : $48-51$.

Cannon PF, Sutton BC (2004) Microfungi on wood and plant debris. In: Mueller GM, Bills GF, Foster MS (Eds) Biodiversity of Fungi: Inventory and Monitoring Methods. Elsevier Academic Press, Boston, 217-239.

Dagamac NHA, Novozhilov YK, Stephenson SL, Lado C, Rojas C, dela Cruz TEE, Unterseher M, Schnittler M. (2017) Biogeographical assessment of myxomycete assemblages from Neotropical and Asian Palaeotropical forests. Journal of Biogeography. 44: 1524-1536. https://doi.org/10.1111/jbi.12985

Estrada-Torres A, Wrigley de Basanta D, Lado C (2013) Biogeographic patterns of the myxomycete biota of the Americas using a parsimony analysis of endemicity. Fungal Diversity 59: 159-177. https://doi.org/10.1007/s13225-012-0209-2

GBIF (2016) https://www.gbif.org/occurrence/search?taxon key=3213078. Accessed on 2016-2-29.

Holdridge LR (1967) Life Zone Ecology. Tropical Science Center, San Jose, Costa Rica, 206 pp.

Höhnel F von (1909) Fragmente zur Mykologie 287. Javanische Myxomyceten. Sitzungsberichte der Kaiserlichen Akademie der Wissenschaften. Mathematisch-naturwissenschafliche Classe 118: 427-442.

Ing B (1982) Notes on Myxomycetes III. Transactions of the British Mycological Society 78 (3): 439-447. https://doi.org/10.1016/ S0007-1536(82)80150-2

Keller H (1973) Myxomycetes from the Everglades National Park and adjacent areas, I. Ohio Journal of Science 73 (6): 364-369.

Kelly, KL (1965) ISCC-NBS Color-Name Charts Illustrated with Centroid Colors. US Department of Commerce, National Bureau of Standards, Circular 553 (Supplement). US Government Printing Office, Washington DC, $40 \mathrm{pp}$.

Lado C, Wrigley Basanta D de (2008) A review of Neotropical myxomycetes (1828-2008). Anales del Jardín Botánico de Madrid 65: 211-254. https://doi.org/10.3989/ajbm.2008.v65.i2.293

Lado C, Wrigley Basanta D de, Estrada-Torres A, Stephenson SL (2013) The biodiversity of myxomycetes in Central Chile. Fungal Diversity 59: 3-32. https://doi.org/10.1007/s13225-012-0159-8.C

Lado, D. Wrigley Basanta D de, Estrada-Torres A, García-Carvajal E (2014) Myxomycete diversity of the Patagonian Steppe and bordering areas in Argentina. Anales del Jardín Botánico de Madrid 71 (1): e0006. https://doi.org/10.3989/ajbm.2394

Lado C, Eliasson U (2017) Taxonomy and systematics: current knowledge and approaches on the taxonomic treatment of myxomycetes: In: Stephenson SL, Rojas C (Eds) Myxomycetes: Biology, Systematics, Biogeography and Ecology. Academic Press, Cambridge, Massachusetts, 205-251.

Lado C (2005-2018) An on line nomenclatural information system of Eumycetozoa. Real Jardín Botánico, CSIC, Madrid. http://www. nomen.eumycetozoa.com. Accessed on: 2017-11-29.

Leontyev DV, Schnittler M, Moreno G, Stephenson SL, Mitchell DW, Rojas C (2014) The genus Alwisia (Myxomycetes) revalidated, with two species new to science. Mycologia 106: 936-948. https:// doi.org/10.3852/13-314

Lister A, Lister G (1904) Notes on mycetozoa from Japan. London Journal of Botany 42: 97-99.

Lister A (1925) A monograph of the Mycetozoa, 3rd ed. revised by G. Lister. British Museum, London, 302 pp.

Martin GW, Alexopoulos CJ (1969) The Myxomycetes. University of Iowa Press, Iowa City. $561 \mathrm{pp}$

Morales RE (2017) Desarrollo de la investigación con mixomicetes en El Salvador a partir de redes profesionales. In: Rojas C (Chair). 
Mixomicetes en Latinoamérica: ¿Hacia dónde van las tendencias de trabajo en nuestra región? Symposium conducted at the meeting of the IX Latin American Mycological Association, Lima, Peru, 46-47.

Nannenga-Bremekamp, NE (1966) Notes on myxomycetes X. Some new species of Licea, Reticularia, Cribraria, Dictydiaethalium, Trichia and Metatrichia. Proceedings van de Koninklijke Nederlandse Akademie van Wetenschappen (Section C) 69: 336-349.

Nannenga-Bremekamp NE, Yamamoto Y, Sharma R (1984) Stemonaria, a new genus in the Stemonitaceae and two new species of Stemonitis (Myxomycetes). Proceedings van de Koninklijke Nederlandse Akademie van Wetenschappen (Section C) 87: 449-469.

Ndiritu G, Haan M de (2014) More additions to the checklist of African myxomycetes. Poster presented at the 8th International Congress on Systematics and Ecology of Myxomycetes, Changchun, Jilin Province, China. https://doi.org/10.13140/RG.2.1.2236.2480

Poulain M, Meyer M, Bozonnet J (2011) Les Myxomycètes. Tome 2. Planches. Fedération Mycologique et Botanique Dauphiné-Savoie, France, 545 pp.

Rammeloo J (1974) Structure of the epispore in the Trichiaceae (Trichiales, Myxomycetes) as seen with the scanning electron microscope. Bulletin de la Société Royale de Botanique de Belgique107:
353-359.

Rammeloo J (1975) Structure of the epispore in the Stemonitales (Myxomycetes) as seen with the scanning electron microscope. Bulletin du Jardin Botanique National de Belgique 45: 301-306.

Ranade VD, Korade ST, Jagtap AV, Ranadive KR (2012) Checklist of myxomycetes from India. Mycosphere 3 (3): 358-390 https://doi. org/10.5943/mycosphere/3/3/9

Rojas C, Stephenson SL, Huxel G (2011) Macroecology of highelevation myxomycete assemblages in the northern Neotropics. Mycological Progress 10: 423-437. https://doi.org/10.1007/s11 557-010-0713-2

Rojas C, Doss RG (2013) Brief research history and conservation implications of myxomycetes from Costa Rica. Brenesia 79: 37-43.

Rojas C, Lado C, Valverde R (2015) First record of the myxomycete genus Colloderma in Central America. Checklist 11 (4): 1-4. https://doi.org/10.15560/11.4.1716

Stephenson SL, Stempen H (1994) A handbook of slimemolds. Timber Press, Portland, Oregon, 200 pp.

Stojanowska W, Panek E (2003) The genus Craterium (Myxomycetes) in Poland. Acta Mycologica 38 (1-2): 65-69. https://doi.org/ 10.5586/am.2003.008 